\title{
Dentinal Pre-Treatment in Restorative Dentistry
}

\author{
Nidhi Manohar Motwani ${ }^{1}$, Anuja Ikhar ${ }^{2}$, Pradnya Nikhade ${ }^{3}$, Manoj Chandak4, Samrudhi Khatod ${ }^{5}$, Saurabh Rathi ${ }^{6}$, \\ Chanchal Rathi ${ }^{7}$
}

\begin{abstract}
${ }^{1}$ Department of Conservative Dentistry and Endodontics, Sharad Pawar Dental College, Sawangi, Wardha, Maharashtra, India. ${ }^{2}$ Department of Conservative Dentistry and Endodontics, Sharad Pawar Dental College, Sawangi, Wardha, Maharashtra, India. ${ }^{3}$ Department of Conservative Dentistry and Endodontics, Sharad Pawar Dental College, Sawangi, Wardha, Maharashtra, India. ${ }^{4}$ Department of Conservative Dentistry and Endodontics, Sharad Pawar Dental College, Sawangi, Wardha, Maharashtra, India. ${ }^{5}$ Department of Conservative Dentistry and Endodontics, Sharad Pawar

Dental College, Sawangi, Wardha, Maharashtra, India. ${ }^{6}$ Department of Conservative Dentistry and Endodontics,

Sharad Pawar Dental College, Sawangi, Wardha, Maharashtra, India. ${ }^{7}$ Department of Conservative Dentistry and Endodontics, Sharad Pawar Dental College, Sawangi, Wardha, Maharashtra, India.
\end{abstract}

\section{ABSTRACT}

\section{BACKGROUND}

The advances in adhesive techniques for bonding dental cements to teeth have long been advantageous in dentistry. Adhesive systems offer retaining areas that permit dental restorations to be placed. Bonding to tooth includes bonding to both enamel and underlying dentin. Adhesion to dentin is the main concern as most of damaged teeth have significant amount of misplaced enamel and require good adhesion to dentin. However, dentin exhibits complex structure which makes it difficult to bond with various materials. Hence to enhance bonding between dentin/tooth and adhesive material, it vital to pre-treat dentin with different gents. Various agents are used to treat dentin before restoration is placed. The agents used are chlorhexidine, sodium hypochlorite, benzalkonium chloride, iodine-based disinfectants, ozone, lasers, glutaraldehyde and proanthocyanidins, added hydrophobic resin layer application, ethanol, biomimetic, remineralizing agents, ethylene diamine tetra acetic acid, polyacrylic acid. 2\% Chlorhexidine digluconate wash has been shown to successfully conserve the bond strength, when etch-and-rinse adhesive systems were used for up to 6 months. This can be due to inhibitory ability of CHX to the matrix metalloproteinases (MMPs) found in etched dentin. Dentinal pre-treatment is also done to eliminate bacteria remaining in cavity wall. $2.5 \% \mathrm{NaOCl}$ pretreatment decreased the shear bond strength (SBS) of self-etch adhesive system and suggested $\mathrm{NaOCl}$ disinfectant to be used with etch-and-rinse bonding systems. The residual bacteria left behind after restorative procedure may endure and multiply which may lead to pulpal irritation, threat of recurrent caries and / or postoperative sensitivity, and therefore leads to failure of the dental restoration. The occurrence of secondary caries is the most common reason for the restorations failures. Attention to the antimicrobial agents and their effects on the pulp began in the early 1970s by Brännström and Nyborg, who focused on the significance of eliminating residual bacteria remaining on cavity walls. Use of $5.25 \% \mathrm{NaOCl}$ solution for 15 seconds to eradicate "Staphylococcus aureus, Candida albicans, Porphyromonas gingivalis, and Prevotella intermedia, Porphyromonas endodontalis. Iodine based compounds have capacity to destroy the bacterial cell by affecting its proteins, nucleotides, and fatty acids. EDTA composition are highly successful in eliminate existing biofilms. It prevents biofilm formation by decreasing the adhesion of bacteria.

This article reviews various agents, their mechanisms of action on dentin, effect on bond strength, their antibacterial activity, effect of agents on pulp, and comparative studies of these pretreatments. Several available agents have various advantages and disadvantages. Therefore, it is necessary to select appropriate agent for better bonding.

\section{KEY WORDS}

Dentinal Pre-Treatment, Chlorhexidine, Sodium Hypochlorite
Corresponding Author: Dr. Nidhi Manohar Motwani, Department of Conservative Dentistry and Endodontics, Sharad Pawar Dental College, Room No. 103, Sawangi, Wardha-442001, Maharashtra, India.

E-mail: nidhimotwani20@gmail.com

DOI: 10.14260/jemds/2020/174

Financial or Other Competing Interests: None.

How to Cite This Article:

Motwani NM, Ikhar A, Nikhade $P$, et al. Dentinal pre-treatment in restorative dentistry. J. Evolution Med. Dent. Sci. 2020;9(10):804-809, DOI: 10.14260/jemds/2020/174

Submission 26-12-2019,

Peer Review 08-02-2020,

Acceptance 14-02-2020,

Published 09-03-2020.

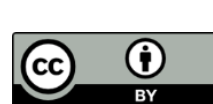




\section{BACKGROUND}

The advances in adhesive techniques for bonding dental cements to teeth have long been advantageous in dentistry. Adhesive systems offer retaining areas that permit dental restorations to be placed. Bonding to tooth includes bonding to both enamel and underlying dentin. ${ }^{1}$ Adhesion to enamel was accomplished through acid etching introduced by Buonocore in 1952. In spite of improvements in materials used for restorative dentistry, there is no material that is ideal. Adhesion to dentin was the main concern as most of damaged teeth have misplaced significant amount of enamel and require good adhesion to dentin. ${ }^{2}$ The mechanical retention of resin is difficult with dentin due to - Firstly, only $40 \%$ of inorganic substance is dissolved during enamel etching by the inorganic acids. Secondly, being living tissue containing dentinal fluid, it is not possible to dehydrate it to the extent necessary to permit sufficient resin infiltration. ${ }^{1}$

Dentin permeability can be measured by hydraulic conductance of dentinal tubules and is related directly to the fourth power of radius of dentinal tubule and inversely related to length of dentinal tubule. ${ }^{3}$ During cavity preparation, dentin is made thin and tubules becomes short and highly conductive as compared to thicker dentin. Thus in such cases, it is hard to manage the outward movement of dentinal fluid that at times interfere with resin bonding. ${ }^{4}$ To increase bond strength of diverse adhesive systems, various dentin pre-treatments have been introduced like acid etching and air abrasion along with glycine application. ${ }^{5}$ Acid etching affects the smear layer and demineralises the dentin. ${ }^{6}$ To avoid dentinal acid etching, air-power polishers might be used as pre-treatment. ${ }^{7}$ After etching the exposed collagen may not be infiltrated by monomer sufficiently and this could occurs in any case of the system applied, with both etchandrinse or self-etch. ${ }^{8}$ Scientific evidences recommend the removing of exposed collagen fibrils as an substitute to the conventional adhesive protocol. ${ }^{9}$ Substances (sodium hypochlorite [ $\mathrm{NaOCl}]$ and collagenase) are able to dissolve exposed collagen after etching which leads to the dentin deproteinization. ${ }^{10}$

The layer formed after dentinal instrumentation, decreases the permeability by $86 \%$ known as smear layer. It covers the dentinal tubules, forming smear plugs. ${ }^{11}$ It acts as barrier to the penetration of resin to underlying dentin. After acid etching there is elimination of the smear layer and smear plugs leading to an increase in fluid flow, which hinder with adhesion. Therefore, dentin is a complicated substrate for bonding. ${ }^{12}$ Dentinal pre-treatment is also done to eliminate bacteria remaining in cavity wall. The residual bacteria left behind after restorative procedure may endure and multiply which may lead to pulpal irritation, threat of recurrent caries and/ or postoperative sensitivity, and therefore leads to failure of the dental restoration. The occurrence of secondary caries is the most common reason for the restoration's failures. ${ }^{13}$ Attention to the antimicrobial agents and their effects on the pulp began in the early 1970s by Brännström and Nyborg, who focused on the significance of eliminating residual bacteria remaining on cavity walls. ${ }^{14}$

The problems associated with microleakage can be magnified by incomplete sterilization of the preparation as a consequence of failure to mechanically remove infected tooth structure. ${ }^{15}$ Some of these agents have been reported to source for pulpal irritation and therefore have been into disuse. ${ }^{16}$

\section{Various Agents Used \\ Chlorhexidine}

Chlorhexidine digluconate ( $\mathrm{CHX}$ ) is a cationic bisbiguanide that has been used as an oral antimicrobial agent introduced in1970s. ${ }^{17}$ And is considered the "gold standard" of oral antiseptics.2\% Chlorhexidine digluconate in aqueous solution is a biocompatible and toxicologically safer disinfectant.18 Pretreatment with Chlorhexidine digluconate has been considered to amplify the accomplishment of pulp-capping procedures. Pameijer and Stanley established that 2\% CHX was a successful hemostatic agent and aid in dentin bridge construction when applied for 60 seconds immediately after contamination of the exposed pulp. ${ }^{19}$ 2\% Chlorhexidine digluconate wash has been shown to successfully conserve the bond strength, when etch-and-rinse adhesive systems were used for up to 6 months. ${ }^{20}$ This can be due to inhibitory ability of CHX to the matrix metalloproteinases (MMPs) found in etched dentin.

The authors found that $\%$ CHX exhibited lower $\mu$ TBS for the self-etch adhesives. Though, the bond strength was not appreciably affected in the etch-and-rinse adhesive groups. The unfavorable effect on bond strength of $2 \%$ CHX solutions associated with self-etch bonding systems and cements may be due to presence of functional monomer (MDP), in the bonding resin of self-etch adhesive systems. ${ }^{21}$ Secondly the remaining moisture of the $2 \% \mathrm{CHX}$ solution alters the capacity of the resin of self-etch system to block the dentin. ${ }^{22}$ CHX also has MMP inhibiting action (against MMP-2, -8 and 9).When CHX was applied to dentin prior etch and rinse adhesives, there was decrease in collagen degradation with time. ${ }^{23}$ The inhibitory action of CHX on MMP is due to chelating action, wherein the appropriation of metal ions like calcium and zinc. It would impede the creation of the catalytic domain within MMPs. ${ }^{24}$

\section{Sodium Hypochlorite}

Sodium hypochlorite is an successful organic solvent. It has been extensively used in dentistry as a cleansing agent. ${ }^{25}$ $\mathrm{NaOCl}$ breaks to sodium chloride and oxygen, leading to oxidation procedure in the dentin matrix. ${ }^{26}$ It also has efficient tissue-dissolving action and good antimicrobial efficacy on residual bacteria. ${ }^{27}$ Vianna et al found the use of $5.25 \% \mathrm{NaOCl}$ solution for 15 seconds to eradicate "Staphylococcus aureus, Candida albicans, Porphyromonas gingivalis, and Prevotella intermedia, Porphyromonas endodontalis." 28 Hilton reported an augmented pulpal response after application of Naocl. ${ }^{29}$ Unlike to these results, it has been considered to be biocompatible with pulp and to encourage pulpal healing,30 with some degree of inflammatory effect only to superficial cells without disturbing the deep pulp tissues.

Ercan et al found that $2.5 \% \mathrm{NaOCl}$ pretreatment decreased the shear bond strength (SBS) of self-etch adhesive system and suggested $\mathrm{NaOCl}$ disinfectant to be used with etch-and-rinse bonding systems. ${ }^{31}$ Fawzy et al showed that tensile bond strength (TBS) of the self-etching adhesive to be decreased by the $\mathrm{NaOCl}$ pretreatment, with no noteworthy effect reported when etch-and-rinse bonding system was used. $\mathrm{NaOCl}$ also removes the organic collagen layer after acid 
conditioning and then bonding to the incompletely demineralized dentin. This may create a more strong bond to the hydroxyapatite present in dentin. ${ }^{32}$ Nagpal et at found that $\mathrm{NaOCl}$ treatment after conditioning with acid, dentin surface showed more deep resin tag formation when viewed under scanning electron microscope. ${ }^{33}$

\section{Benzalkonium Chloride}

It is a mixture of alkyl benzyl dimethyl ammonium chlorides and is a cationic agent with broad antimicrobial activity which contains a quaternary ammonium group. ${ }^{34}$ Tubulicid (Global Dental Products, Bellmore, NY, USA) is a quaternary ammonium compound with ethylene-diamine tetra acetic acid (EDTA).It comes in three form: Tubulicid Red; Tubulicid Blue and Tubulicid Plus. Although BAC is a strong antibacterial agent against microorganisms like S. mutans, Streptococcus salivarius, and S. aureus. ${ }^{35}$ But was reported to be less efficient than CHX. Like CHX, BAC is also a useful MMP inhibitor that may protect the resin-dentin interface. ${ }^{36}$

Based on two in vitro studies, Sharma et al suggested that Tublicid Red should be used only with etch-and-rinse bonding systems. ${ }^{37}$ In disparity to the results of Sharma et al, Türkün et al found that Tubulicid Red do not considerably influence the sealing capability of Prompt L-Pop and Clearfil SE Bond. ${ }^{38}$ At high concentration, Benzalkonium chloride solutions can be reason for allergic reactions and toxic effects, and at concentration of $10 \%$ or more if ingested, severe adverse effect may occur which may even cause death. ${ }^{39}$

\section{Iodine-Based Disinfectants}

Iodine-based compounds have antibacterial effects due to molecular iodine present in these solutions ${ }^{40}$ Different iodine solutions have been used for disinfection purpose, includes: Iodine -potassium iodide, potassium iodide/copper sulfate, iodine disclosing/disinfection solution, and povidone-iodine. They have the capacity to destroy the bacterial cell by affecting its proteins, nucleotides, and fatty acids. ${ }^{41}$ Simratvir et $\mathrm{al}^{42}$ studied $S$. mutans counts in children with early childhood caries and found that 10\% PVP-I significantly reduced S. mutans counts after 12 months of treatment. Da Silva et al found the effect of $2 \%$ I2DDS on $\mu$ TBS to be significantly decreased for ethanol- and water-based adhesive systems, but did not affected acetone based adhesives. ${ }^{43}$ The major side effects of iodine based compounds is iodine hypersensitivity. ${ }^{44}$ It is contraindicated during pregnancy and thyroid disorders because it alters the metabolic process in body. 45

\section{Lasers}

Lasers are devices that give off beams of various wavelengths. Laser irradiation causes extension of present in intratubular areas, water content of the bacterial cell and has thermal and photo disruptive lysis. ${ }^{46}$ de Sousa Farias et al found that lowlevel laser using antimicrobial photodynamic therapy (aPDT) drastically decreased the viable bacterial counts in the S. mutans biofilm. ${ }^{47}$ The drawback of laser irradiation on pulpal tissues and other soft tissues is affected by many factors, such as the temperature and the degree of the absorbed energy, wavelength, and exposure time.48 Many studies have suggested that the lasers does not negatively manipulate the bond strength of the restoration using Er, Cr: YSGG or KTP.49 Celik et al report that use of the Er, Cr: YSGG laser mainly as a cavity disinfectant was found to considerably increase the $\mu$ TBS when used with etch-and-rinse bonding system as compared with those not pre-treated or bonded with selfetch adhesive. ${ }^{50}$ Barbakow $\mathrm{F}$ et al showed that both Er: YAG and Nd: YAG laser were effective for smear layer removal. The energy of laser is absorbed by water which evaporates the water and ablates the molecules of the specimen i.e dentin. However, the Nd: YAG laser is inadequately absorbed by water; so Er: YAG was more effective. ${ }^{51}$ Negi et al (2015) showed that Nd: YAG laser with an energy ranging from 150 to $87.5 \mathrm{~mJ} /$ pulse has shown a bactericidal effect suppressing and eradicating putative periodontal pathogens from periodontal pockets as well as from dental hard tissues. ${ }^{52}$

\section{Ozone}

Ozone (03) is a unstable gas, which breaks down s into activated oxygen atoms. ${ }^{33}$ Since ozone is a strong oxidizer, it destroys the cell wall of bacteria and therefore act as antibacterial agent. 54 The antimicrobial efficacy of 03 in opposition to oral microorganisms, especially against $\mathrm{S}$. mutans, has been well recognized in the text. For effective antimicrobial action 03 application varies from $10-60$ seconds. ${ }^{55}$ Cehreli et al established that with 03 pretreatment, there was significant reduction in micro leakage. ${ }^{56}$ Günes et al suggested 03 to be more booming as a cavity disinfectant than conventional methods. In their study, as compared to groups pre-treated with $\mathrm{CHX}, \mathrm{BAC}, \mathrm{NaOCl}$, and diode lasers, the micro leakage was observed least in the 03-treated group. ${ }^{57}$ The major drawback of 03 treatment clinically is cost as compared to other disinfectant.

\section{Naturally Based Disinfectants}

Curiosity in the using of natural therapeutics as a substitute to conventional medicine in dental applications has been rising in modern years. ${ }^{58}$ Various disinfectants have been used and studied for their antimicrobial action and their response on restorative procedures. These consist of propolis, Salvadora persica, and Morinda citrifolia.

\section{Glutaraldehyde and Proanthocyanidins}

Glutaraldehyde, a extensively being synthetic cross-linking agent, can improve bond strength and stability but it present some drawbacks like toxicity. The cross-linking agents causes increase in mechanical properties and stabilization of dentin collagen. It also decrease enzymatic breakdown and therefore lead to improving the bond strength. Also type I collagen provides with tensile strength, form, and cohesiveness to tissues and organ. ${ }^{59}$ Glutaraldehyde solutions act by fixation of the cell membrane and block the release of cellular components and thus kill the microorganisms. ${ }^{60}$ Proanthocyanidins are a type of bioflavonoid that are in nature occurring as plant metabolites available in fruits and vegetables. ${ }^{61} \mathrm{PA}$ do not have toxic effects and are recognized to stabilize and raise type- 1 collagen fibrils cross linking.

\section{Added Hydrophobic Resin Layer Application}

The efficiency of one-step self-etch bonding system may be enhanced by treating them as a separate primer and casing it with a hydrophobic layer of resin such as in traditional etch \& rinse bonding system. Firstly, the added use of hydrophobic resin coating raise the percent of hydrophobic monomers present, dropping the virtual percent of solvents and 
hydrophilic monomers. ${ }^{62}$ Secondly, the applying hydrophobic layer also prevent dispersion of water throughout the hybrid layer to the adhesive-resin boundary. That could reduce polymerization and also cause weaking of the adhesive-resin composite boundary. Thirdly, the extra layer of hydrophobic adhesive enlarge the width of the adhesive layer which leads to further decrease in polymerisation 63 .

\section{Ethanol}

Although the integration of hydrophilic resin monomers has enhanced the ability of current adhesive systems to bond with wet dentin substrates, however it shows increased water sorption and rapid weakening of the mechanical properties, affecting the durability of resin-dentin bonds. Current studies have revealed that it is promising to bond resin monomers to acid-etched dentin with ethanol-wet bonding technique. 64 This technique is introduced for the purpose of etch\& rinse adhesives, that includes the most important perception of slowly replacement of water present in interfibrillar and intrafibrillar spaces inside the demineralized collagen matrix. In this procedure, ethanol which is a polar solvent, causes chemical desiccation of the demineralized collagen. This causes reduction of the collagen fibrils increasing the interfibrillar spaces, for monomers to penetrate the matrix more optimally. 65

\section{Biomimetic Remineralizing Agents}

The most convincing problem related to resin dentin bonds is their inadequate durability. Remineralization by biomimetic agents of exposed collagen fibrils is another approach for reinforcement of bond between resin-dentin. The biomimetic remineralization protocol was introduced by Tay and Pashley, which includes the combining of two biomimetic similar to dentin collagen so that the doped collagen can direct the distribution of apatite remineralization. ${ }^{66}$ The remineralizing agent includes Portland cement or simulated body fluid system containing polyacrylic acid (PAA) and poly vinyl phosphonic acid (PVPA) as biomimetic substitute for amorphous calcium phosphate.

\section{Ethylene Diamine Tetra Acetic Acid}

Ethylene diamine tetra acetic acid (EDTA) is an acid with a chelating effect and can seize di- and trivalent metal ions. The group responsible for metal bonding are carboxylate and amine groups. ${ }^{67}$ EDTA composition are highly successful in eliminate existing biofilms. It prevent biofilm formation by decreasing the adhesion of bacteria. According to Caron et al., the combination of $17 \%$ EDTA and $3 \% \mathrm{NaOCl}$ combination removed the smear layer more powerfully. ${ }^{68}$ It has been shown to release bioactive growth factor from dentin thus stimulating differentiation of odontoblast. The orthophosphoric acid had superior smear layer removal action in less application time than EDTA.

\section{Polyacrylic Acid}

Polyacrylic acid is commonly used conditioner for GICs because it is capable of cleansing the dentin surface without completely unplugging the dentinal tubules ${ }^{69}$. It has milder action than phosphoric acid. Different concentration used are $10 \%, 20 \%, 25 \%$. Hotz et al. were the first who reported increase in bond strength of GIC to dentin by application of
PAA (25 per cent) after 30 seconds. ${ }^{69}$ Its mechanism of action includes following-

- due to cleansing action removing the loose cutting debris following cavity preparation.

- due to partial demineralization effect rising the surface area and creating micro porosities.

\section{CONCLUSIONS}

The dentinal pre-treatment therefore helps in achieving cavity disinfection and enhances the bond between tooth and restorative material.

\section{REFERENCES}

[1] Jones SEB. The story of adhesion and developments in dentistry. Int J Adhesion and Adhesives 1995;15(2):10913.

[2] Panchbhai A. Nanocomposites: past, present and future of dentistry. In: Applications of nanocomposite materials in dentistry. Woodhead Publishing 2019: p. 181-90.

[3] Merchant VA, Livingston MJ, Pashley DH. Dentin permeability: comparison of diffusion with filtration. J Dent Res 1977;56(10):1161-4.

[4] Pashley EL, Talmann R, Horner JA, et al. Permeability of normal versus carious dentine. Endod Dent Traumatol 1991;7(5):207-11.

[5] Manuja N, Nagpal R, Pandit IK. Dental adhesion: mechanism, techniques and durability. J Clin Pediatr Dent 2012;36(3):223-34.

[6] Scotti N, Rota R, Scansetti M, et al. Fiber post adhesion to radicular dentin: the use of acid etching prior to a onestep self-etching adhesive. Quintessence Int 2012;43(7):615-23.

[7] Borsatto MC, Catirse ABEB, Dibb RGP, et al. Shear bond strength of enamel surface treated with air-abrasive system. Braz Dent J 2002;13(3):175-8.

[8] Carvalho RM, Chersoni S, Frankenberger R, et al. A challenge to the conventional wisdom that simultaneous etching and resin infiltration always occurs in self-etch adhesives. Biomaterials 2005;26(9):1035-42.

[9] Prati C, Chersoni S, Pashley DH. Effect of removal of surface collagen fibrils on resin-dentin bonding. Dent Mater 1999;15(5):323-31.

[10] Nagpal R, Tewari S, Gupta R. Effect of various surface treatments on the microleakage and ultrastructure of resin-tooth interface. Oper Dent 2007;32(1):16-23.

[11] Pashley DH, Livingston MJ, Greenhill JD. Regional resistances to fluid flow in human dentine, in vitro. Arch Oral Biol 1978;23(9):807-10.

[12] Mahrous AM, Eltiti HA, Ahmed IM, et al. Effect of different gingival margin restorations of class II cavities on microleakage: an in-vitro study. Electron Physician 2015;7(7):1435-40.

[13] Rathi NV, Chandak MG, Mude GA. Comparative evaluation of dentinal caries in restored cavity prepared by galvanic and sintered burs. Contemporary Clinical Dentistry 2018;9(Suppl 1):S23-S7. 
[14] Brännström M, Nyborg H. Cavity treatment with a microbiocidal fluoride solution: growth of bacteria and effect on the pulp. J Prosthet Dent 1973;30(3):303-10.

[15] Pattanaik N, Chandak M. The effect of three cavity disinfectants (chlorhexidine gluconate-based. Consepsis: benzalkonium chlorite-based, Tubulicid red: sodium hypochlorite based-Chlorcid $\mathrm{V}$ on the self-etch dentine bonding agent (Adeper Easy One, 3M ESPE) under SEM. Journal of Dental and Medical Sciences (IOSR-JDMS) 2013;8(5):84-9.

[16] Shafiei F, Memarpour M. Antibacterial activity in adhesive dentistry: a literature review. Gen Dent 2012;60(6):e346-e56, quiz p. e357-8.

[17] Silla MP, Company JMM, Silla JMA. Use of chlorhexidine varnishes in preventing and treating periodontal disease: a review of the literature. Med Oral Patol Oral Cir Bucal 2008;13(4):E257-E60.

[18] Mohammadi Z, Abbott PV. The properties and applications of chlorhexidine in endodontics. Int Endod J 2009;42(4):288-302.

[19] Pameijer CH, Stanley HR. The disastrous effects of the "totalEtch" technique in vital pulp capping in primates. Am J Dent 1998;11:S45-S54.

[20] Francisconi-dos-Rios LF, Casas-Apayco LC, Calabria MP, et al. Role of chlorhexidine inbond strength to artificially eroded dentin over time. J Adhes Dent 2015;17(2):133-9.

[21] Shafiei F, Memarpour M. Antibacterial activity in adhesive dentistry: a literature review. Gen Dent 2012;60(6):e346-e56, quiz p. e357-8.

[22] Singla M, Aggarwal V, Kumar N. Effect of chlorhexidinecavity disinfection on microleakage in cavities restored with composite using a self-etching single bottle adhesive. J Conserv Dent 2011;14(4):374-7.

[23] Breschi L, Mazzoni A, Nato F, et al. Chlorhexidine stabilizes the adhesive interface: a 2-year in vitro study. Dent Mater 2010;26(4):320-5.

[24] Sorsa T, Tjaderhane L, Konttinen YT, et al. Matrix metalloproteinases: contribution to pathogenesis, diagnosis and treatment of periodontal inflammation. Annals Med 2006;38(5):306-21.

[25] Spencer HR, Ike V, Brennan PA. The use of sodium hypochloritein endodontics - potential complications and their management. Br Dent J 2007;202(9):555-9.

[26] Tulunoglu O, Ayhan H, Olmez A, et al. The effect of cavity disinfectants on micro leakage in dentin bonding system. J Clin Pediatr Dent 1998;22(4):299-305.

[27] Gomes BP, Ferraz CC, Vianna ME, et al. In vitro antimicrobial activity of several concentrations of sodium hypochlorite and chlorhexidine gluconate in the elimination of Enterococcus faecalis. Int Endod J 2001;34(6):424-8.

[28] Vianna ME, Gomes BP, Berber VB, et al. In vitro evaluation of the antimicrobial activity of chlorhexidine and sodium hypochlorite. Oral Surg Oral Med Oral Patho Oral radio Endod 2004;97(1):79-84.

[29] Hilton TJ. Keys to clinical success with pulp capping: a review of the literature. Oper Dent 2009;34(5):615-25.

[30] Cox CF, Hafez AA, Akimoto N, et al. Biological basis for clinical success: pulp protection and the tooth restoration interface. Pract Periodontics Aesthet Dent 1999;11(7):819-26.
[31] Ercan E, Erdemir A, Zorba YO, et al. Effect of different cavity disinfectants on shear bond strength of composite resin to dentin. J Adhes Dent 2009;11(5):343-6.

[32] De Saboia VPA, Pimenta LAF, Ambrosano GMB. Effect of collagen removal on microleakage of resin composite restorations. Oper Dent 2002;27(1):38-43.

[33] Nagpal R, Tewari S, Gupta R. Effect of various surface treatments on the microleakage and ultrastructure of resin-tooth interface. Oper Dent 2007;32(1):16-23.

[34] Sabatini C, Pashley DH. Aging of adhesive interfaces treated with benzalkonium chloride and benzalkonium methacrylate. Eur J Oral Sci 2015;123(2):102-7.

[35] Turkun M, Ozata F, Uzer E, et al. Antimicrobial substantivity of cavity disinfectants. Gen Dent 2005;53(3):182-6.

[36] Sabatini C, Kim JH, Alias OP. In vitro evaluation of benzalkonium chloride in the preservation of adhesive interfaces. Oper Dent 2014;39(3):283-90.

[37] Sharma V, Nainan MT, Shivanna V. The effect of cavity disinfectants on the sealing ability of dentin bonding system: an in vitro study. J Conserv Dent 2009;12(3):109-13.

[38] Türkün M, Türkün LS, Kalender A. Effect of cavity disinfectants on the sealing ability of non-rinsing dentinbonding resins. Quintessence Int 2004;35(6):469-76.

[39] Hitosugi M, Maruyama K, Takatsu A. A case of fatal Benzalkonium Chloride poisoning. Int J Legal Med 1998;111(5):265-6.

[40] Athanassiadis B, Abbott PV, Walsh LJ. The use of calciumhydroxide, antibiotics and biocides as antimicrobial medicamentsin endodontics. Aust Dent J 2007;52(Suppl 1):S64-S82.

[41] Haapasalo M, Endal U, Zandi H, et al. Eradication of endodontic infection by instrumentation and irrigation solutions. Endod Topics 2005;10(1):77-102.

[42] Simratvir M, Singh N, Chopra S, et al. Efficacy of $10 \%$ povidone iodine in children affected with early childhood caries: an in vivo study. J Clin Pediatr Dent 2010;34(3):233-8.

[43] Da Silva NR, Calamia CS, Coelho PG, et al. Effect of $2 \%$ Iodine disinfecting solution on bond strength to dentin. J Appl Oral Sci 2006;14(6):399-404.

[44] Twetman S. Antimicrobials in future caries control? A review with special reference to chlorhexidine treatment. Caries Res 2004;38(3):223-9.

[45] Mohan PV, Uloopi KS, Vinay C, et al. In vivo comparison of cavity disinfection efficacy with APF gel, propolis, diodelaser and $2 \%$ chlorhexidine in primary teeth. Contemp Clin Dent 2016;7(1):45-50.

[46] De Sousa FSS, Nemezio MA, Corona SAM, et al. Effects of low-level laser therapy combined with toluidine blue on polysaccharides and biofilm of Streptococcus mutans. Lasers Med Sci 2016;31(5):1011-6.

[47] Dimitrov S, Dogandzhiyska V, Ishkitiev N. Effect of laser irradiation with different wavelength on the proliferation activity of human pulp fibroblast cells, depending on irradiation parameters and hard tissue thickness. J IMAB 2009;15(2):28-31.

[48] Siso HS, Kustarci A, Göktolga EG. Microleakage in resin composite restorations after antimicrobial pretreatments: effect of KTP laser, chlorhexidine gluconate and Clearfil Protect Bond. Oper Dent 2009;34(3):321-7. 
[49] Celik C, Ozel Y, Bağiş B, et al. Effect of laser irradiation and cavity disinfectant application on the microtensile bond strength of different adhesive systems. Photomed Laser Surg 2010;28(2):267-72.

[50] Barbakow F, Peters O, Havranek L. Effects of Nd: YAG lasers on root canal walls: a light and scanning electron microscopic study. Quintessence Int 1999;30(12):83745.

[51] Negi S, Krishnamurthy M, Ganji KK, et al. Modulatory effects by neodymium-doped yttrium aluminum garnet laser on fibroblast attachment to single rooted tooth surfaces following ultrasonic scaling and root planning: an in vitro study. Journal of Indian Society of Periodontology 2015;19(1):25-31.

[52] Naik SV, Rajeshwari K, Kohli S, et al. Ozone - a biological therapy in dentistry - reality or myth? Open Dent J 2016;10:196-206.

[53] Kapdan A, Öztaş N. Effects of chlorhexidine and gaseous ozone on microleakage and on the bond strength of dentin bonding agents with compomer restoration on primary teeth. J Dent Sci 2015;10(1):46-54.

[54] Fagrell TG, Dietz W, Lingström P, et al. Effect of ozone treatment on different cariogenic microorganisms in vitro. Swed Dent J 2008;32(3):139-47.

[55] Cehreli SB, Yalcinkaya Z, Guven-Polat G, et al. Effect of ozone pretreatment on the microleakage of pit and fissure sealants. J Clin Pediatr Dent 2010;35(2):187-90.

[56] Günes Ş, Bahsi E, İnce B, et al. Comparative evaluation of the effects of ozone, diode laser, and traditional cavity disinfectants on microleakage. Ozone Sci Eng 2014;36(2):206-11.

[57] Little JW. Complementary and alternative medicine: impact on dentistry. Oral Surg Oral Med Oral Pathol Oral Radiol Endod 2004;98(2):137-45.

[58] Yamauchi M. Collagen biochemistry: an overview. In: Phillips GO, edr. Advances in tissue banking. Vol. 6. New Jersey: World Scientific 2002: p. 455-500.

[59] Nimonkar SV, Belkhode VM, Godbole SR, et al. Comparative evaluation of the effect of chemical disinfectants and ultraviolet disinfection on dimensional stability of the polyvinyl siloxane impressions. Journal of International Society of Preventive \& Community Dentistry 2019;9(2):152-8.

[60] Joshi SS, Kuszynski CA, Bagchi D. The cellular and molecular basis of health benefits of grape seed proanthocyanidin extract. Curr Pharm Biotechnol 2001;2(2):187-200.

[61] Albuquerque M, Pegoraro M, Mattei G, et al. Effect of double-application or the application of a hydrophobic layer for improved efficacy of one-step self-etch systems in enamel and dentin. Oper Dent 2008;33(5):564-70.

[62] Tay FR, Pashley DH, Suh BI, et al. Single-step adhesives are permeable membranes. J Dent 2002;30(7-8):371-82.

[63] Pashley DH, Tay FR, Carvalho RM, et al. From dry bonding to water-wet bonding to ethanol-wet bonding. A review of the interactions between dentin matrix and solvated resins using a macromodel of the hybrid layer. Am J Dent 2007;20(1):7-20.

[64] Tay FR, Pashley DH, Kapur RR, et al. Bonding BisGMA to dentin - a proof of concept for hydrophobic dentin bonding. J Dent Res 2007;86(11):1034-9.

[65] Gajjerman S, Narayanan K, Hao J, et al. Matrix macromolecules in hard tissues control the nucleation and hierarchical assembly of hydroxyapatite. J Biol Chem 2007;282(2):1193-204.

[66] Wiberg E, Holleman AF, Wiberg N. Inorganic Chemistry. San Diego: Academic Press 2001. ISBN 0-12-352651-5.

[67] Caron G, Nham K, Bronnec F, et al. Effectiveness of different final irrigant activation protocols on smear layer removal in curved canals. J Endod 2010;36(8):1361-6.

[68] Abdalla AI. Morphological interface between hybrid ionomers and dentin with and without smear-layer removal. J Oral Rehabil 2000;27(9):808-14.

[69] Hotz P, McLean JW, Sced I, et al. The bonding of glassionomer cements to metal and tooth substrates. Br Dent J 